\title{
Rendering Etymological Variation Of Medical Terminology
}

\author{
Roksolana Povoroznyuk \\ Department of Theory and Practice of Translation into English, Taras Shevchenko National University, Kyiv 01030, Ukraine
}

\begin{abstract}
This article explores the problem of rendering etymological variation of medical terminology. Its findings are based on the comparative analysis of the original and translated versions of “The Physician” by N. Gordon (translated into Russian by Vladimir Polyakov). The aim of the present study is to corroborate the hypothesis that the etymology of medical terms' translation correspondences is a prerequisite defining the adequacy of the target text. Resorting to the etymological variation, by contrast, denotes the SL (source language) or TL (target language) bias of the translation strategy. To achieve this aim, we used the following methods: descriptive statistical analysis of terminological units in order to assess their etymological correspondence to the original units, distributional analysis of the translation techniques and procedures with a statistical analysis of their frequency. Results of the study suggest that the medical terminology is rendered by borrowings (34.65\%) more often than by terminological variants signaling communicative translation procedure (28.71\%). The footnotes, manifestations of the amplification strategy (22.78\%), and calques (13.86\%) are used to ensure understanding of the target audience. This distribution of techniques and procedures reveals a predominant SL bias of the translation.
\end{abstract}

Key words: etymological variation, medical terminology, translation strategies, translation procedures, SL bias, TL bias.

\section{Introduction}

Medical terminology is an important and inalienable element of the LSP (Language for Specific Purposes) studies, and its significance is underscored by the fact of the EMP (English for Medical Purposes) being incorporated within the frameworks of various university syllabi [1]. However, its analyses are by no means exhaustive. According to Andrews et al., the study of medical English from the standpoint of the philologist is nearly a virgin field [2]. The status, functions and etymological features of medical terminology in the hybrid texts combining characteristics of various discourses (medical tracts versus popular medical fiction, professional versus lay communication etc.) are pending their in-depth exploration, especially in view of their translation.

The problem of rendering medical terminology per se has been analyzed by such scholars as Gile and

Corresponding author: Roksolana Povoroznyuk, Ph.D., assistant professor, research field: medical translation and translation studies. E-mail: rocksol24@yandex.ru.
Rouleau. Gile suggests that medical texts contain such complex cognitive notions as to be absolutely inaccessible for the lay reader/unprofessional translator $[3,4]$. Nevertheless, Rouleau admits that while the main function of medical translation is to convey the message of a scientific text, the idiomatic and emotional components are not to be overlooked [5].

In a presentation on rhetoric of translation in science and technology, Iljinska et al. claims that "to communicate a certain idea in a scientific and technical text, it is necessary to use definite codes, which govern the discourse of a certain field, scientific or technical discipline and even professional communication at large" [6]. The loss of such codes in translation would lead to an inevitable transformation of the rhetorical function of the target text.

\section{Aim of the Study}

The aim of our study is to corroborate the hypothesis that the etymology of medical terms' translation correspondences is a prerequisite defining the 
adequacy of the target text. Resorting to the etymological variation, by contrast, denotes the SL (source language) or TL (target language) bias of the translation strategy.

\section{Materials and Methods}

The material for our research is drawn from the novel by Noah Gordon "The Physician" (translated into Russian by Vladimir Polyakov). Our choice is explained by its popularity in Europe which resulted in numerous translations and purchase of the film rights; another reason is the preponderance of Latin and Greek medical terminology, primarily of the archaic nature, which allows us to explore the temporal aspects of etymological variation.

Etymological classification of the medical terms in translation is presented according to the pattern by Herget and Alegre. The scholars assert that borrowed medical terms (of a Greek or Latin origin) are typical of an erudite communication, and thus are used in translations made for the professionals. On the other hand, if the target text is addressed to the general audience, the translator should make use of lexemes originating in his/her native tongue [7].

Contrastive analysis was used to assess the degree of target language text's correspondence to the source language text. Transformational analysis was based on Molina and Hurtado Albir's list of the following translation techniques [8]. The methodology of rendering cultural-specific medical terms follows the arrow-graph of the SL and TL biases outlined by Montalt et al. [9].

\section{Results}

Dircks observes that "the language of modern American medicine is an amalgam of words and roots from dozens of ancient and modern languages, a distillate of three thousand years of cultural and linguistic evolution and of almost as long a period of scientific and technical progress" [10]. However, within its rich arsenal of borrowings the wide margin is built up by the Latin and Greek lexemes, reflecting the evolution of the medical science from the ancient to medieval times [11]. From a practical standpoint, Latin and Greek terms and term-building elements possess a high distribution valency, rich and varied semantics and self-contained, economical nature [12].

Lefevere sees the translator borrowing the source language text's defining features (such as medical terminology) as "his national literature's 'antenna', picking up new and unfamiliar sounds" [13]. This literal approach to translation is partially supported by Neubert's assertion that "sometimes translator intentionally wants to keep the target text aloof from textual integration into the prevalent discourse of the target culture" [14].

Nevertheless, the literal rendering of etymologically divergent elements (SL bias) often leads to an impasse when the target audience does not have the scope of background knowledge required for understanding the original term. In this case, a translator is supposed to produce acceptability-oriented translations in order to meet the requirements of the target culture receiving the translated version of the text.

Direct transfer of the Greek or Latin-originating lexemes into the target language version manifests the translation technique of borrowing [8] or the cultural borrowing translation procedure [9]: contenta, or undissolved components [15, p.411] - contenta, то есть нерастворившихся составляющих [16, р.444]. (back-translation: contenta, which means undissolved components).

The calques are used in the Russian version of "The Phycisian" when the TL traditions demanded it (сонная артерия (back-translation: carotid artery) [16] — carotid arteries in the neck [15], «кровопускание» (back-translation: bloodletting) [16] — phlebotomy — bloodletting [15]). Some of the lexemes in the text are only provisional diagnostic nominations of a descriptive character (quasi-terms) which are also rendered by means of calques (rheum sickness [15]—боль в суставах [16] (back-translation: 
joint ache), the kind of heat sickness [15]—что-то вроде солнечной болезни [16] (back-translation: something similar to a sun-induced sickness).

Bekisheva et al. point out the fact that sometimes the lexical motivation behind the Greek or Latin-originating term is obscure and requires delving into its etymology [17]. In these instances, the translator makes use of footnotes which, according to Molina et al.'s classification, belong to the group of amplification techniques [8]. Nida posits that the footnotes (1) correct linguistic and cultural differences or (2) provide additional information about the historical and cultural context of the text in question [18]. In their turn, Montalt et al. give no indication of footnoting among their list of translation procedures [9]:the urine glass, which he had told them was properly called a matula. It was bell-shaped [15]—стеклянный сосуд для мочи, который имел латинское название matula. Сосуд имел форму колокола [16] (back-translation: a glass urine jar having a Latin name of matula. The jar had a shape of a bell). The passage has an attached footnote: $\varkappa^{1}$ Горшок(лат.).»(back-translation: ${ }^{1} \mathrm{Pot}$ (Latin)) [16].

The footnotes are less productive for rendering medical terminology as they are viewed as the metatext appending the original but barely affecting its nature. To the same extent, compressions and reductions are avoided when the medical terminology is concerned, as reducing the overall readability of the end-product (translated text).

Every language is characterized by the parallel presence of several etymologically-divergent nominations for the same concept. This phenomenon has long been a bone of contention for the linguists: for instance, Wills opines that "terminological doublets are undesirable, because they contradict the postulate of one-to-one correspondences between the extralinguistic matter and linguistic denotation" [19]. On the other hand, Dircks asserts that "no language can remain pure for long unless its speakers live in total isolation" [10]. The consensus in the matter lies not in the evaluation of the terminological variability as a notion, but rather the degree of its prevalence in each of the linguistic systems. Having compared the medical terminologies in English and Russian, Trofimova draws a conclusion that the English terminology is characterized by the variability of the Latin borrowings and their derivatives while its Russian counterpart combines the Latin-originating lexemes with their native correspondences (very often created from the old Slavic roots) [20]. An interesting aspect of the interlingual terminological variability becomes evident as the diagnostic nominations of the original and target texts are put side by side. The English lexemes turn out to have the Latin-originating equivalents in Russian. However, the translator opts for the descriptive paraphrases in order to convey the medieval flavor of the original (quinsy [15] is rendered by «остроe воспаление горла» (back-translation: acute throat inflammation) [16] instead of a more precise diagnostic nomination «острый, гнойный тонзиллит» (back-translation: acute purulent tonsillitis), thrush [15] by an archaic term «гнилостная болезнь» (back-translation: putrid disease) [16] instead of «афтозный стоматит» (back-translation: aphthous stomatitis).

These transformations of the original message amount to what Molina et al. referred to as linguistic variation: changes of textual tone, style, social or geographical dialect etc. [8]; however, as they affect the field of terminology, they might be rightfully named "terminological variations". By contrast, Montalt et al. suggest the procedure of communicative translation when "the source language referent has an identifiable correspondence in the target language that is not a literal translation" [9].

The data above can be summarized in Table 1 and Fig.1.

\section{Discussion}

The overall distribution of the translation techniques 
Journal of US-China Medical Science 12 (2015) 40-44

doi: 10.17265/1548-6648/2015.01.006

Table 1 The ratio of translation techniques and procedures used for the rendering of medical terminology in the Russian version of the "The Physician" by Gordon.

\begin{tabular}{|c|c|c|c|c|c|}
\hline \multicolumn{3}{|c|}{ Translation techniques } & \multicolumn{3}{|c|}{ Translation procedures } \\
\hline & Number of instances & Percentage ratio & & Number of instances & Percentage ratio \\
\hline Borrowing & 35 & 34.65 & Cultural borrowing & 35 & 44.87 \\
\hline Calque & 14 & 13.86 & Calque & 14 & 17.95 \\
\hline Footnote (Amplification) & 23 & 22.78 & Not indicated & - & - \\
\hline Terminological variation & 29 & 28.71 & $\begin{array}{l}\text { Communicative } \\
\text { translation }\end{array}$ & 29 & 37.18 \\
\hline Total number of instances & 101 & 100 & Total number of instances & 78 & 100 \\
\hline
\end{tabular}

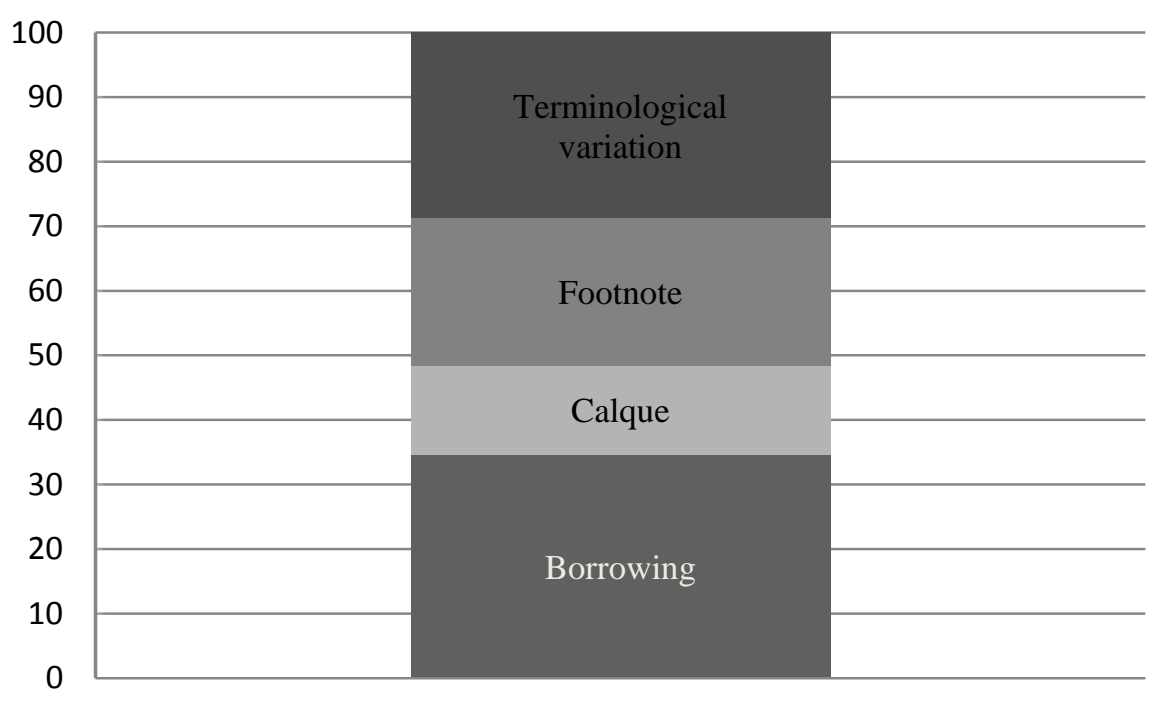

Translation technique

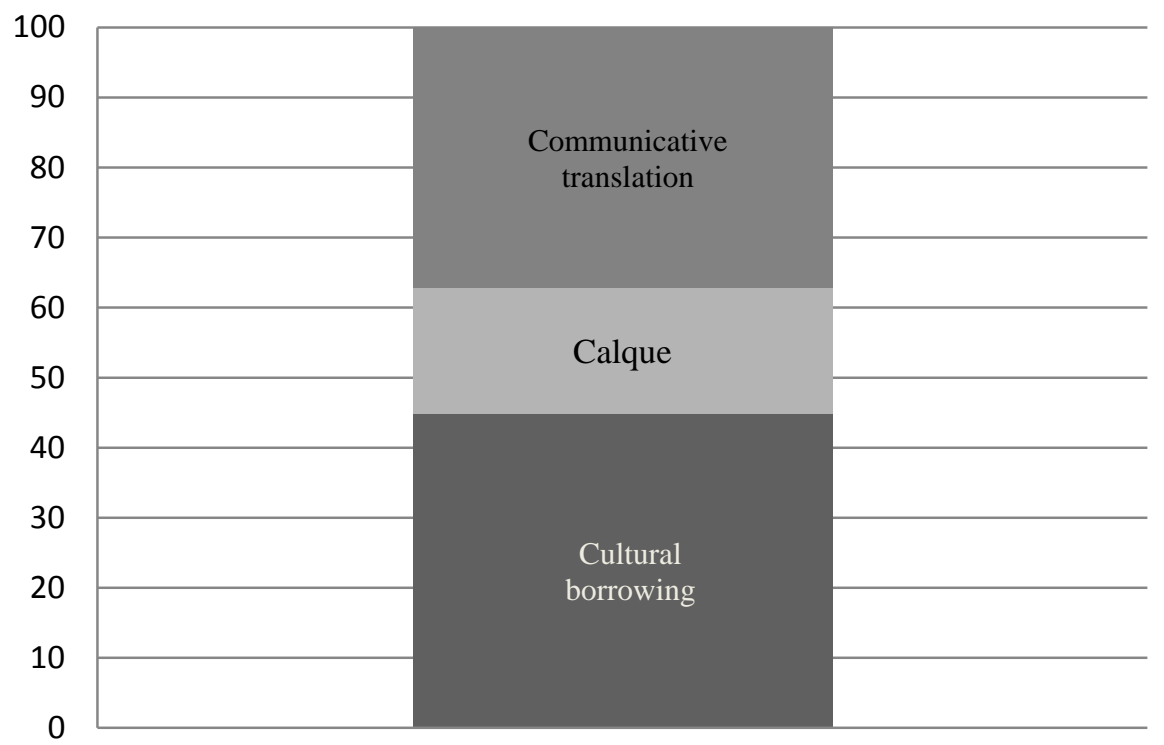

Translation procedure

Fig. 1 Percentage distribution of the translation techniques and procedures used for the rendering of medical terminology in the Russian version of the “The Physician” by Gordon. 
and procedures indicates the SL bias of the translation strategy. The translator seeking to preserve the message and flavor of the original text integrated its terminological elements into the Russian version (preponderance of borrowings, use of calques). However, the issue of target audience's response is also a priority; hence the use of footnotes and communicative translation procedures. Unlike the former, they are viewed as appending the original but barely affecting its nature.

Although our results cannot be extrapolated to all the texts due to a limited corpus, they shed some light on the translation methodology and factors influencing the translator's decision-making. However, further studies of translation strategies applicable for the etymologically diverse medical terminology are required, with a particular focus on evaluation parameters of the translation's quality.

\section{References}

[1] Antic, Z. 2007. "Forward in Teaching English for Medical Purposes.” Facta Universitatis. Series: Medicine and Biology 14 (3): 141-7.

[2] Andrews, E., and Luckhardt, A. B. 1947. A History of Scientific English: The Story of Its Evolution Based on a Study of Biomedical Terminology. NY: Richard R. Smith.

[3] Gile, D. 1986. "The Medical Translation: Should It Be Limited to the Doctors-Translators? Some Reflections.” META 31 (1): 26-30. (in French)

[4] Gile, D. 2005. Translation: To Understand it, to Learn it. Paris: Presse Universitaires de France. (in French)

[5] Rouleau, M. 2003. "Medical Terminology and Its Problems”. Panace@. IV (12): 143-52. Accessed December

12 , 2014.http://www.medtrad.org/panacea/IndiceGeneral/n12 _tribuna_Rouleau.pdf. (in French)

[6] Iljinska L., Platonova M., and Smirnova T. 2014. "Rhetoric of Translation in Science and Technology." In Proceedings of the 59th Annual ILA Conference "The Linguistics of Rhetoric and Debate”, 14.

[7] Herget, K., and Alegre, T. 2009. "Translation of Medical Terms.” Translation Journal 13 (3). Accessed December 12 , 2014. http://www.translationjournal.net/journal/49medical1.htm
[8] Molina L., and Albir, A. H. 2002. "Translation Techniques Revisited: A Dynamic and Functionalist Approach” META. 47 (4): 498-512.

[9] Montalt, V., and Gonzalez-Davies, M. 2007. Medical Translation Step by Step: Learning by Drafting. Abingdon: Taylor \& Francis.

[10] Dirckx, J. H. 1976. The Language of Medicine: Its Evolution, Structure and Dynamics. Hagerstown, Maryland: Harper \& Row.

[11] Ariza, M. A. A. 2012. "The English of the Health Sciences: A Note on Foreign Borrowings.” The ESPecialist 33 (1): 67-90.

[12] Gushchina L. N. 2004. "Comparative Analysis of Russian and English Medical Terminology Used in the Oncological Field.” Ph.D. thesis, Moscow State Regional University. Accessed December 12, 2014. http://www.dslib.net/sravnit-jazykoved/sravnitelno-sopos tavitelnyj-analiz-medicinskih-terminov-v-oblasti-onkolog ii-v.html. (in Russian)

[13] Lefevere, A. 1975. Translating Poetry: Seven Strategies and a Blueprint. Amsterdam: Van Gorkum.

[14] Neubert, A. 2001. "Some Implications Regarding Translations as Hybrid Texts.” Across Languages and Cultures 2 (2): 181-93.

[15] Gordon, N. 2013. The Physician. Barcelona: Barcelona Digital Editions.

[16] Gordon, N. 2013. The Physician. Avicenna's student. translated by Polyakov, V. Khar'kov, Belgorod: Klubsemeynogodosuga. (in Russian)

[17] BekishevaYe.V., Ugnich K. A. 2014. "Historical and Evolutionary Aspects of Medical Lexis.” Moscow State Linguistic Institute Public Library. Accessed December 12, 2014

http://tplislu.ru/publ/terminovedenie/obshhie_svedenija/is toriko_ehvoljucionnye_aspekty_medicinskoj_leksiki/361-0-143. (in Russian)

[18] Nida, E. A. 2003. Towards a Science of Translation, with Special Reference to Principles and Procedures Involved in Bible Translating. Leiden: Brill.

[19] Wilss, W. 1996. Knowledge and Skills in Translator Behavior. Amsterdam, Philadelphia: John Benjamins.

[20] Trofimova N. A. 2004. "Aspects of Adopting the Latin Borrowings by the Specialized Terminological Systems: Based on the Russian, English and German Medical Terminology.” Ph.D. thesis, Saratov State Academy of Law. Accessed December 12, 2014. http://cheloveknauka.com/osobennosti-osvoeniya-zaimstv ovannoy-latinskoy-leksiki-v-otraslevoy-terminosisteme. (in Russian) 